\title{
A flexible, open, and interactive digital platform to support online and blended experiential learning environments: Thinglink and thin sections
}

\author{
Adam J. Jeffery ${ }^{1}$, Steven L. Rogers ${ }^{1}$, Kelly L. A. Jeffery ${ }^{2}$, and Luke Hobson ${ }^{1}$ \\ ${ }^{1}$ School of Geography, Geology, and the Environment, Keele University, Keele, Staffordshire, ST5 5BG, UK \\ ${ }^{2}$ School of Life Sciences, Keele University, Keele, Staffordshire, ST5 5BG, UK
}

Correspondence: Adam J. Jeffery (a.j.jeffery@keele.ac.uk)

Received: 27 October 2020 - Discussion started: 2 November 2020

Revised: 31 December 2020 - Accepted: 19 January 2021 - Published: 16 March 2021

Abstract. This study investigates the potential value of, and provides a method for, the creation of flexible, digital, and asynchronous platforms to create student-centred materials for use in an online and/or blended learning environment. We made use of Thinglink to create a "virtual microscope" resource for geology and associated courses in higher education. This is achieved through the dissemination of a simple learning resource comprising interactive imagery and audio.

The visual analysis of rocks under the microscope, termed thin-section petrography, is a fundamental component in geology programmes in higher education, with key skills which are transferable with other fields such as material science, biology, and forensic science. However, learning environments and activities in this field are often dictated by the requirement for access to microscope facilities and supplementary resources which are highly variable in their academic level, availability, design, and scale, ranging from traditional textbooks to online resources.

A resource was created which allows individuals to experience some of the aspects of petrographic microscopy in a digital manner. In particular, specific features of the materials observed and how microscopes work were included. The resource was disseminated to a population of learners and educators, who provided responses to a questionnaire. Responses were overwhelmingly positive and indicate considerable interest from learner and teacher alike. Critical areas for improvement include the need for clarity in the user interface and the inclusion of a recorded human voice rather than automated text narration. This study highlights the need for, and benefits of, interactive online learning resources in petrology and associated fields. This type of resource has positive implications for the flexibility, inclusivity, and accessibility of teaching materials. Such resources may prove particularly valuable when distance learning is unavoidable (e.g. the COVID-19 crisis) and/or hybrid, blended learning environments are being deployed. The method and platform used in this study are highly transferable to other subject areas (or other areas of the geosciences).

\section{Introduction}

The fields of petrology, mineralogy, and geochemistry (PMG fields), which collectively deal with the origin, classification, and composition of rocks, form an integral component in the broad field of geology or geoscience (e.g. Reinhardt, 2004; Mogk, 2007). To achieve competence in these academic fields, individuals need to acquire key skills, such as the ability to accurately describe and classify rocks based on their mineralogical and geochemical composition. Arguably one of the most fundamental techniques available for this purpose is thin-section petrography, a branch of geology which originated with Henry Clifton Sorby in the mid-19th century (Folk, 1965) and which relies heavily on techniques such as optical microscopy and, in the modern day, scanning electron microscopy. Of these, the latter is dependent upon expensive, specialist facilities, which introduces some limitations on its potential for teaching due to purchase and running costs, as well as availability of instrumentation for individual learning, requiring resource management and learning resource creation to mitigate accessibility restrictions and remove barri- 
ers to success (e.g. Shin, 2004; Childers and Jones, 2015). By contrast, optical microscopy requires comparatively cheap facilities (polarizing light microscopes), and it is common for individual learners in large groups or classes to be able to undertake independent study with their own microscope (e.g. Penn et al., 2007). Specimens for study are cut and polished, typically to a thickness of $30 \mu \mathrm{m}$, and although this invariably has its own costs, prepared samples will not deteriorate with due care and will be suitable for use for many future student cohorts. As such, optical microscopy remains one of the most fundamental analytical techniques which is available to geoscientists, beginners, and experts alike (Reinhardt, 2004), providing vital skills which are applicable not only to petrology, but also to forensic science, biological science, medical technology, material science, metallurgy, economic geology, environmental science, and the increasingly recognized and valued field of environmental geology (Gunter, 2004), amongst others.

Over the past few decades (and in some cases prior to that), individuals involved in the development of educational materials across a range of academic fields have sought to implement novel technologies available to them at the time (Manduca, 2007; Pringle, 2015). These include simulated fieldwork (e.g. Argles et al., 2015; Houghton et al., 2015), e-gaming (e.g. Squire, 2008; Pringle, 2013, 2014), and virtual reality (e.g. Domingo and Bradley, 2018; Rogers, 2020). This is also true of PMG fields, where educators have supplemented their teaching with additional resources, such as manuals of microscope images (photomicrographs) (e.g. Riley Brice and Hawkins Lint, 1987; Choh and Milliken, 2004), digital tutorials (e.g. Milliken et al., 2003), and computer programmes and packages such as the Open University's Virtual Microscope Project (http://www.virtualmicroscope.org, last access: 3 March 2021), among many others (e.g. Frost, 1977; Ariskin and Nielsen, 1993; Emley et al., 1998; Palmer et al., 1999), analogue experiments (e.g. Brady, 2009), and integration of published research materials (e.g. research-led teaching; Peck, 2004), as well as fundamental changes to course design and structure (e.g. Reinhardt, 2004; Perkins, 2005).

The overall aims of this project are as follows:

1. to design a high-quality, inclusive, interactive learning resource, using high-resolution imagery and digital videos, which can supplement existing resources and contribute to the diversification of teaching techniques within the geoscience fields, including traditional and environmental geology;

2. to provide not only considerable accessibility, inclusivity, and interactivity, but also a level of in-built guidance and support that is typically unavailable in classical petrology teaching (and certainly outside of the traditional class setting) and which often represents one of the greatest difficulties associated with distance learning (e.g. Waddoups and Howell, 2002);
3. to allow users to undertake learning in a user-friendly environment in which they can employ different learning approaches at their own pace to an area of geoscience which is often regarded as one of the most challenging;

4. to demonstrate the benefits of such resources during times when alternatives to distance learning are limited and to identify the most important means of developing and improving these resources over time.

This approach adheres to the concept of blended and/or hybrid learning, i.e. the combining of instructional modalities (Bonk and Graham, 2012), providing multiple forms of teaching that can better support a range of learning styles within the cohort (e.g. Graham, 2006, and references therein). It is beneficial to the learner, who can access the resource with comparative ease relative to expensive textbooks, or classrooms and associated facilities, which can only be accessed at certain times. Learners can also access the resource from their own home, at a time of their own choosing, and can undertake the activities provided at their own pace and with no time restrictions. It is similarly valuable for the educator, due to the potential pedagogic benefits of moving from transmissive to interactive teaching (e.g. Domagk et al., 2010) and also the enhanced cost-effectiveness compared with traditional teaching techniques. Although the construction of this resource predates the current (at time of writing) COVID-19 health crisis, it may provide some justification for the implementation of such resources.

\section{Project background and context}

The fundamental aim of teaching petrography (and similar activities in other STEM disciplines) is to allow trained specialists to accurately describe, classify, and interpret rocks (or their equivalent in other disciplines) using hand specimens and thin sections. As such, the intended learning outcomes of higher education modules incorporating petrography (typically petrology, mineralogy, or geochemistry-based modules) frequently include the following:

- Develop experience in the correct use of a polarized light microscope.

- Identify the common rock-forming minerals and their relative abundances in rock hand specimens and thin sections, creating detailed scientific sketches that adequately summarize the key features of the sample.

- Identify key microstructural and textural relationships between different minerals and/or clasts.

- Interpret the geological history of rocks based on mineral, sediment, and clast assemblages and textures. 
- Assign names/classifications to rock samples based on mineralogical and textural characteristics using the appropriate classification scheme.

In practice, these skills are typically taught via practical classes, in which learners are provided with a polarizing microscope and a variety of hand specimens and thin sections and are tasked with describing and sketching the samples, identifying key features, and allocating an appropriate name. Additional support typically comes in the form of assistance from teaching staff and laboratory demonstrators, handouts prepared by the course designer(s), and direction to an external resource such as an online resource or a key textbook, which is not necessarily easily accessible to all students, particularly those requiring screen readers or speech recognition software. As such, a great deal of the available support is local and specific to the teaching institution and dependent upon the time available for staff to generate materials. This inevitably leads to considerable diversity between educational institutions, with some educators preferring highly "experimental" or innovative approaches to petrography teaching and others preferring highly traditional or "classical" approaches. Below, we describe some of the external learning resources that are currently (or have been) available to the modern student of petrography, such as key textbooks, freely available literature and teaching activities, and online resources.

\subsection{Currently available learning resources}

As discussed above, the field of petrography is not without supplementary resources which are available to all learners across the field (i.e. not created within, and exclusively available to, individual educational institutions). These can be broadly categorized into textbooks, online resources, and interactive online resources. The former represents the oldest and most traditional approach and generally forms the staple form of support provided, via reading lists and book recommendations, for petrography courses. However, recommended texts frequently suffer from problems associated with their academic level, either being too complex and detailed or lacking in detail. For example, frequently recommended classic texts such as MacKenzie and Guildford (1980), Gribble and Hall (1992), MacKenzie and Adams (1994), and Barker (2014), to name a few, commonly suffer from a range of intrinsic problems, despite their superb quality and content. For example, students may struggle to access them due to the costs involved in their acquisition, their potentially limited availability in libraries, or the need for books to be converted into accessible formats for students with print disabilities. Once published, the books cannot be updated unless another edition is published; the examples chosen are (understandably) some of the best examples globally available but may not represent a true reflection of the natural diversity of specimens. Furthermore, the costs of publishing have historically limited the overall size of such materials, as well as the availability of colour images, restricting the number of examples that could be provided for each topic (e.g. the number of images of a specific mineral in thin section). In the authors' experience, a key problem in the learning of petrography is the overdependence of learners on single thinsection images during mineral identification; a learner might struggle to appreciate the diversity of appearances, colours, and textures that could be exhibited by the same mineral in thin section when a recommended text is only able to provide one or two example images. Similarly, the disconnect between text and static imagery introduces further complications; a learner who cannot understand what the text is describing will not be able to recognize the feature in the image. By contrast, some textbooks may appear too complex for learners due to their high density of information, some of which may be too specialist for the learner. For example, the widely utilized textbook by Deer et al. (1966), now in its third edition, is rightly recommended for learners on PMG courses and contains a wealth of information relating to optical mineralogy and mineral identification. However, this abundance of information, much of which is aimed more at the professional user, can be off-putting and indeed overwhelming to student learners. In short, textbooks offer a fundamental, if somewhat generic resource with clear benefits in terms of information density and images but represent a ridged approach to supporting learning due to accessibility issues, as well as their relatively (and unavoidably) static nature.

Online resources offer a complementary alternative to textbooks, generally lacking the overall scale found in textbooks but being easy to update and access. They typically take the form of electronic documents, slide show presentations, video demonstrations, animations, and websites, typically created and maintained by educators and researchers in higher education and shared online. The "Teach the Earth" portal of the website for the Science Education Resource Centre at Carlton College, USA (http://www.serc.carleton. edu/teachearth, last access: 18 June 2020), is a particularly good example of a compilation of online resources and teaching materials, including comprehensive PDF documents, PowerPoint presentations, animations, and innovative pre-built teaching exercises. These resources offer a variety of forms that complement a range of learning styles, are frequently much more user-friendly than textbooks, and are easier to share, collaborate on, and update than standard textbooks, enhancing their accessibility. However, they can be somewhat specific to the curriculum at the designer's host institution, and even the largest and most comprehensive atlases of thin-section images remain inevitably static, which may have implications for fostering student engagement.

Interactivity in learning activities is widely regarded to be beneficial to deep learning (e.g. Hannafin and Peck, 1988; Moreno et al., 2001; Mayer et al., 2003; Evans and Gibbons, 2007; Writh, 2007; Domagk et al., 2010). The most prominent example of an interactive petrography learning re- 
source is the Virtual Microscope for Earth Sciences Project (VMESP), hosted by the Open University, UK (e.g. Anand et al., 2012). The resource comprises more than 400 rock samples from across the world, which can be viewed in hand specimens via high-quality photographs or in thin section via high-resolution photomicrographs. Summary information of the origin and make-up of each sample is provided, as well as links to external sources, and user interactivity is provided by allowing users to navigate by finding samples on Google Maps, as well as zooming in and out of thin-section images and changing from plane- polarized light (PPL) to crosspolarized light (XPL). In some cases, the interactive experience is enhanced with pre-built "hotspots", which allow the user to zoom in on a specific feature and rotate a virtual stage to observe key effects. The VMESP has generated a superb resource which greatly enhances the accessibility of geological samples for educational purposes. One area in which this study aims to build upon the Virtual Microscope is to enhance interactivity and provide a component of more direct instructional support and guided learning. This is achieved through the addition of multiple hotspots (see Sect. 3 below), which provide key images, information, and links to external information, as well as the addition of a voice-over narrative, effectively providing audio instruction and support, thus catering to different approaches to learning and student needs.

\subsection{The Thinglink platform}

The Thinglink web resource (Thinglink, 2018) is an education and recreational technology platform based around the augmentation of images and videos to create interactive, visual learning experiences. The platform allows the user to upload images and add a variety of hotspots, which, when clicked on, can provide additional images, text, audio files, or links to other images. The user may also upload $360^{\circ} \mathrm{im}-$ ages or videos, which can be augmented in the same manner and viewed with Google ${ }^{\mathrm{TM}}$ goggles or VR headsets. The final product is a flexible and navigable resource with multiple images and/or videos linked together in a (hopefully) coherent manner. When a resource has been completed, it can be disseminated to potential learners via a link (alternatively the resources can be shared as visual links or embedded within other online platforms), which will provide immediate access. Although there are some restrictions on the maximum number of visitors to an individual project, this is dependent upon the form of license held, which needs only to be held by the educational establishment, not the learner (a free licence, with reasonably restricted numbers of permitted viewers, is available). As a learning platform, Thinglink has numerous applications and has gained attention in recent years in teaching and outreach (e.g. Appasamy, 2018; Nakatsuka, 2018/19). There are particularly powerful applications for Thinglink in the geosciences and associated subjects (e.g. STEM disciplines), particularly for virtual field- work and visual-based topics (anatomy, for example). The application of Thinglink to virtual fieldwork, in particular, has considerable potential for increasing accessibility of the field and has gained particular relevance in light of the limitations exacerbated by the COVID-19 health crisis (and similar situations) (e.g. Granshaw and Duggan-Haas, 2012; Pringle, 2015; Cliffe, 2017; Stokes et al., 2019). Resources can be as generic or as specialized as required, and their application to other areas of the geosciences which are dependent upon students being physically present in a given location at a specific time (e.g. petrography, laboratory-based geochemistry) would have similarly considerable benefits to teaching in this field.

\section{Method and implementation}

\subsection{Creating digital learning resources in Thinglink}

Three geological thin sections were selected for use in the prototype (Fig. 1). To maximize user engagement, the selected sections (basalt, andesite, and rhyolite) were chosen from a number of different rock types that are frequently used for introductory petrography courses and which are, in the authors' experience, often considered to be a suitable compositional range for introductory-level volcanology-themed teaching. Considerable effort was made to ensure that the images were high-quality, due to the highly visual nature of the resource (Dutrow, 2007). These thin sections were imaged under PPL and XPL using a Nikon Eclipse LV100N POL microscope with a camera attachment. In each case, approximately 80 individual images were collected per sample, which were then stitched together using Adobe Photoshop ${ }^{\mathrm{TM}}$ (version CS2) to form high-resolution images. The final images were then uploaded to Thinglink (version Premium), where they were used to construct an interactive learning environment (Fig. 2). Additional images were collected via photography to provide material for a "workstation-themed" title page (Fig. 2a) and an additional page to provide key information of the features of a petrological microscope. Each thin-section image was populated with hotspots which either provide information and enhanced imagery relating to a specific feature of the sample or act as a link (Fig. 2b). The links were used in multiple ways; a link back to the home page was added to act as a "home" button. Similarly, a link was added to each page to allow movement between a PPL and XPL image of the same sample, effectively allowing users to toggle between the two forms of light, which is an important feature of petrographic microscopy. Finally, a link was added to each sample which provided summary information on the rock sample itself, as well as a link to a more comprehensive external information source, hosted by https://geology.com/ (last access: 3 March 2021), where considered beneficial, digital video footage of specific petrographical features (e.g. mineral colour changes during rotation of the microscope stage) was collected using the same Nikon Eclipse micro- 
scope, alongside a freely available screen-recording software package (Fig. 2c). Information was added to the images in the form of clickable icons which led to text, images, and videos highlighting key features to be observed in the sample, as determined by the author. All of the text was converted to audio using the text-to-voice function within the Thinglink platform, recorded separately, and added to the relevant interactive elements within the learning environment to provide automatic audio commentary for the key features of each sample. The audio commentary was attributed to a created character, named "Petra", to enhance inclusivity and promote meaningful learning (Moreno et al., 2001). A simple map displaying the overall structure and layout of the resource is shown in Fig. 3. The prototype resource can be found at https: //www.thinglink.com/card/1289204509796466691 (last access: 8 March 2021).

The structure of the learning resource is designed to adhere to the concepts of "experiential learning" (e.g. Kolb et al., 2001; Kolb and Kolb, 2005; Kolb, 2014) and "scaffolding" (e.g. Young, 1993). By maximizing the degree of simulation in the design of the resource, for example by creating a "workbench" home page, the learner gains critical experience in navigating a rock sample in thin section. As such, the learner is actively involved in the identification of minerals and textures in thin section, rather than being reliant upon the comparatively cumbersome application of text-based theory, such as optical properties. This has the added benefit of allowing the learner to work backwards if they wish, confirming their own theory-based conclusions by seeing the example first. The addition of a strongly guided element effectively provides scaffolding (see Young, 1993, for background), preventing the learner from being faced with the daunting task of interpreting and classifying an image alone. Instead, they can be instructed by clicking on the bespoke interactive elements whilst being able to navigate freely through the resource in their own time. With this in mind, the learners should be able to achieve the first two levels of Bloom's Revised Taxonomy (Anderson et al., 2001; Krathwohl, 2002), namely "remember" and "understand". The user should be able to recognize various common microscopic features of rocks, identifying different minerals and textures. They should then be able to compare the different samples, classifying them based on their observations and explaining to some extent what the features could mean. The transition to the next step of the taxonomy ("apply") could be easily achieved with the next logical step in this resource, namely the addition of quiz-style elements in which the learners can test their knowledge, implementing their prior experience to undertake some simple identification of classification tasks without direct aid.

\subsection{Collection of feedback}

The prototype learning resource was disseminated to the potential users via a link provided in an e-mail invitation. The provided link gave potential users (including undergraduate and postgraduate students enrolled on geoscience-based degree programmes, as well as university academic staff members) direct access to the learning resource via personal computer, laptop, or tablet, without any requirement for payment, licence, or registration. The invitation provided information on the nature of the resource, as well as the reasons for its development, and offered an opportunity to provide anonymous feedback that would be used to further develop the resource. Alongside the invitation, an additional link was provided which gave access to a Google form comprising nine questions for feedback. The questions were selected to cover a range of specific topics relating to the overall benefit of using such a learning resource, including applicability, accessibility, relevance to the target degree courses, and overall quality. The final question permitted users to provide any further qualitative information, comments, or suggestions via a text input box. It was made clear that no personal data would be collected, that all responses would be treated anonymously, and that engagement was on a strictly voluntary basis. All data collected in the form as of 15 June 2020 were compiled and are presented below. To facilitate a critical comparison of student and staff users, two parallel Google forms were used, retaining user anonymity.

\section{Results}

The data collected in the survey are summarized in Fig. 4 and Table 1. In total, there were 26 responses, divided between 6 students and 20 staff members. Although this is not a large or evenly distributed cohort, it does serve as a preliminary dataset and a proof of concept, particularly considering the predominantly positive responses received. For clarity, question responses of "agree" or "strongly agree" will be termed positive, responses of "disagree" or "strongly disagree" will be termed negative, and responses of "neither agree nor disagree" will be termed neutral. From this feedback an in-depth version of the resource has been created, with more examples of thin sections and a wider range of information and content.

Overall, student users were exclusively positive in their responses to questions $1-5$ and 7-8, and the majority of staff were also positive in their responses, with $96 \%$ responding positively, $3 \%$ neutrally, and $1 \%$ responding with "not applicable" (Fig. 4). Question 6 gave users the opportunity to indicate any other fields of petrography (other than the igneous samples which were included in the prototype) which they felt would be equally suitable for a learning resource such as the one provided. As a whole, student users were arguably slightly more interested in diversifying the materials in the resource, with all six of the respondents favouring the inclusion of metamorphic and carbonate sedimentary rocks, and five of the six users advocating the addition of clastic sedimentary rocks and microfossils. By contrast, 17 of the 20 staff responses were in favour of including both 

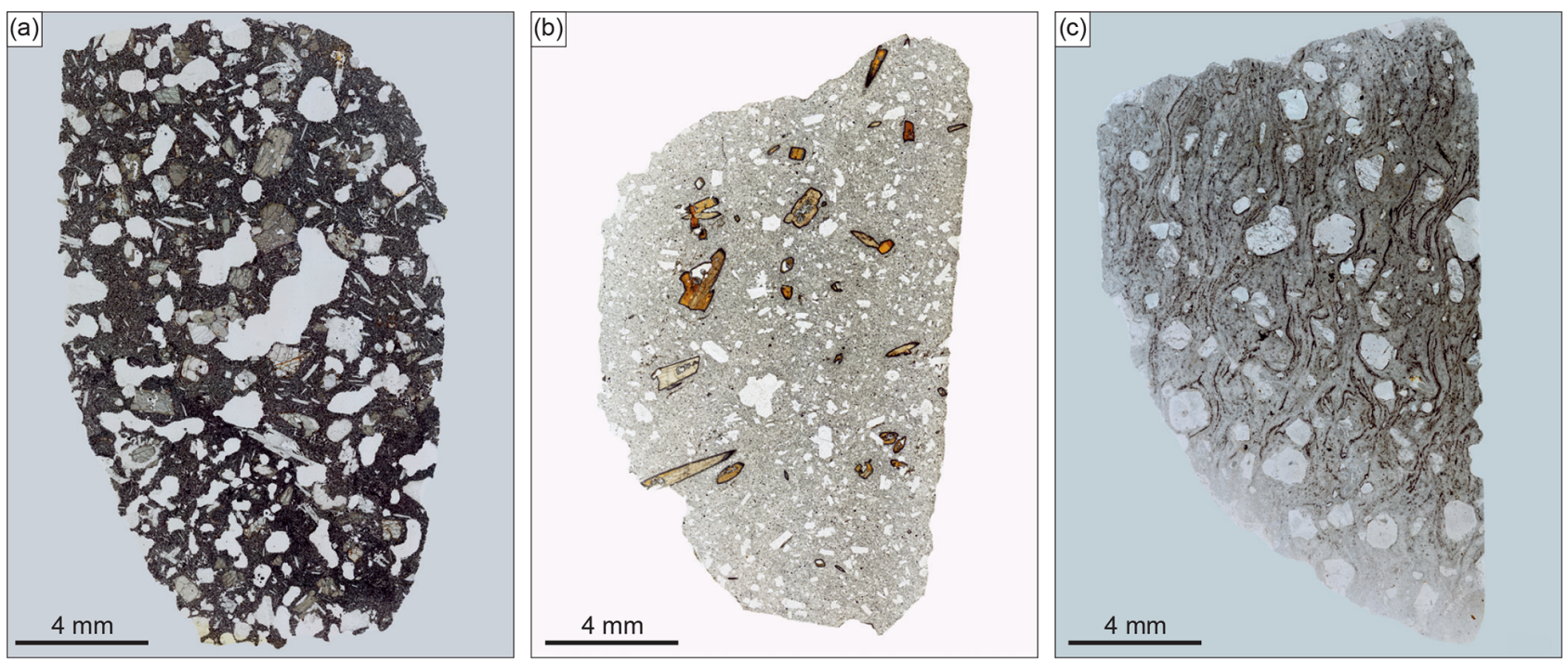

Figure 1. Thin section samples selected for use in the prototype learning resource: (a) basalt, (b) andesite, and (c) rhyolite.

carbonate rocks and microfossils, with 16 and 15 responses in favour of adding clastic and metamorphic rocks, respectively. Question 9 gave the users the opportunity to provide any other feedback, comments, or suggestions that they felt had not been adequately handled through the other questions (Table 1). As observed for the other questions, the responses were broadly positive, although there are two key recurring themes amongst the suggestions: (1) user-interface-related problems such as the purpose and placement of the different hotspot icons and (2) problems associated with the audio narration (Petra), such as finding the computer-generated voice and accent grating or annoying.

\section{Discussion}

In this section, the results of this study will be discussed and reflected upon within the context of four major themes, which relate directly to the aims of the project: (1) accessibility and inclusivity, (2) clarity and quality, (3) applicability and pedagogic value, and (4) continued resource development.

\subsection{Theme 1: accessibility and inclusivity}

For a technology-based learning activity such as this to function correctly, it needs to be accessible and inclusive (Selwyn, 2007). Educators have a duty to provide reasonable adjustments under the guidelines of the Equality Act 2010 (Legislation.gov.uk, 2010), and so any learning resources used must be accessible for those with additional needs, such as print disabilities (e.g. visual impairment, cerebral palsy, paralysis), and those with dyslexia, or easily adaptable to make them so. This can be achieved through the application of assistive technology tools, such as screen readers, which can highlight and read text out to the user (e.g. JAWS, Dolphin SuperNova), text-to-audio converters, which convert documents into alternative media including audio books, ebooks, and digital Braille (e.g. SensusAccess), programmes which add text to images, providing better image context (e.g. ALT text in pictures), and speech recognition software, which converts spoken word to text (e.g. Dragon). Many of these forms of support require licences for operation, with an inevitable cost which must be paid by either the user, the academic institution, or third-party funders (e.g. Disabled Students' Allowance).

This theme was evaluated using questions 1 and 2, considering how accessible the learning resource is for its users. This includes not only the direct accessibility of the resource (e.g. ability of different users to access via a number of different media and locations), but also its overall user-friendliness and ease of use for different users with a range of abilities. User response data for this theme were positive, with an almost exclusively positive response to both questions. However, a number of users highlighted key areas for improvement relating to the user interface (UI), typically relating to either the placement and design of the hotspots (lack of clarity over use of different symbols) or the academic level of the material (e.g. use of specific terminology and abbreviations). For example, users no. 6, 7, 9, 11, 14, and 17 identified confusion with the use of both the question mark and magnifying glass symbols (Table 1). Ultimately, these issues which were identified are easily resolvable via the integration of "keys" or introductory sections which make the structure and format of the resource clear.

Overall, the resource has clear potential to provide a level of accessibility and inclusivity that cannot necessarily be achieved through traditional classroom-based microscopy and associated text-based supplementary materials. 

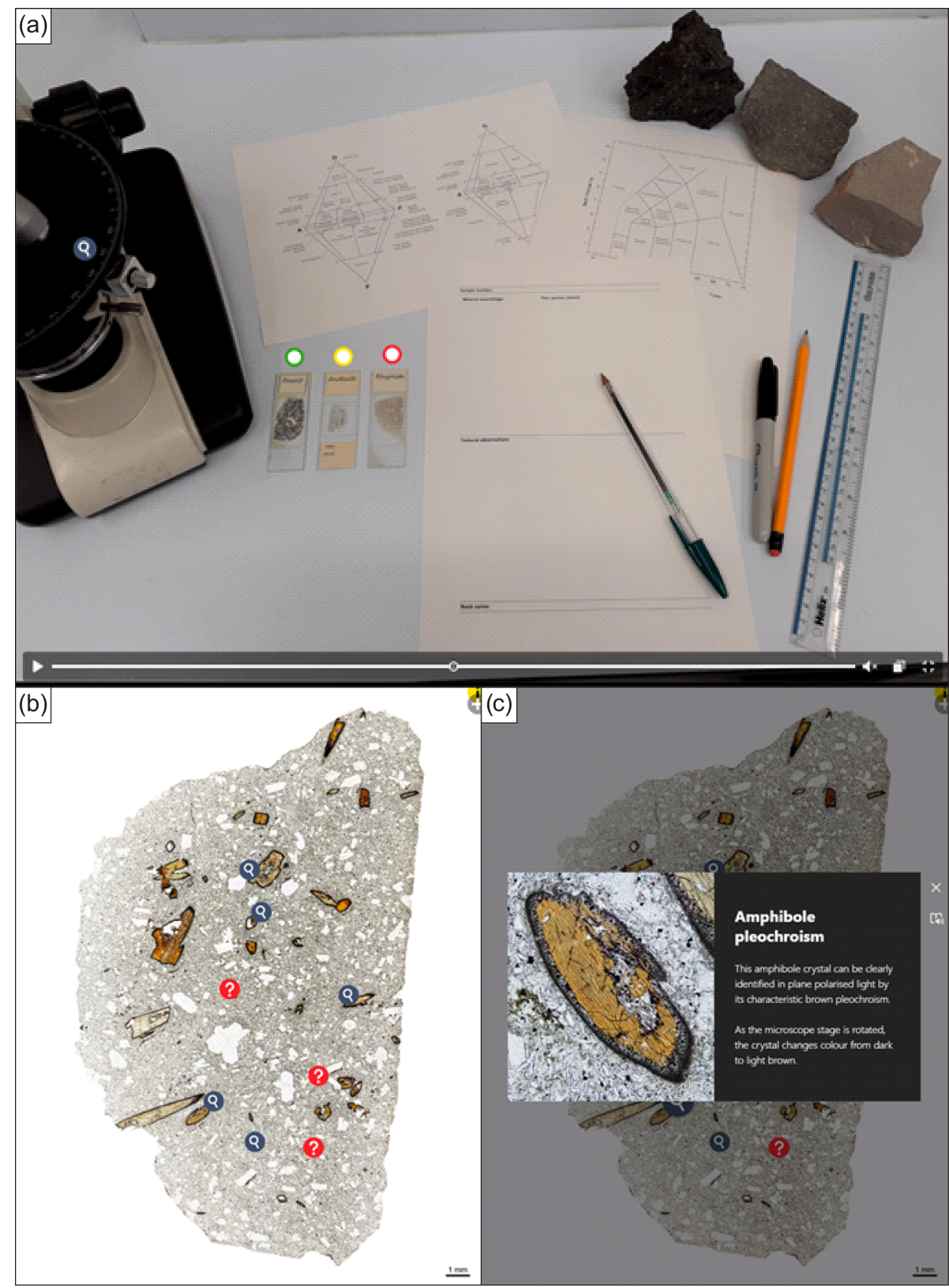

Figure 2. Images taken from the Thinglink-based learning resource created for, and utilized by, this study. (a) The title page of the learning resource designed to mimic a typical workstation for a petrography student. (b) An example high-resolution thin-section image with multiple clickable hotspots. (c) An example of a text and video description which can be activated by clicking on a hotspot.

Resources such as this represent a critical step towards digital, blended learning environments. The selected platform (Thinglink) offers a positive resolution to a number of inclusivity issues, such as access to a microscope. The learning resource can be made freely available via public dissemination of the appropriate link and, with some minor user interface changes, can be easily accessed and navigated. Furthermore, the resource allows users to undertake the exercise at their own pace without the time constraints and associated pressures of the classroom environment (response 4, Table 1).
The only potential limiting factor to accessibility is the general requirement for internet access. However, there are options with this platform to download resources and view them offline, which may, with further exploration, provide a mitigation to this problem. The incorporation of similar technologies typically applied in assistive technology tools (e.g. audio narration) should greatly enhance the inclusivity of the resource. 


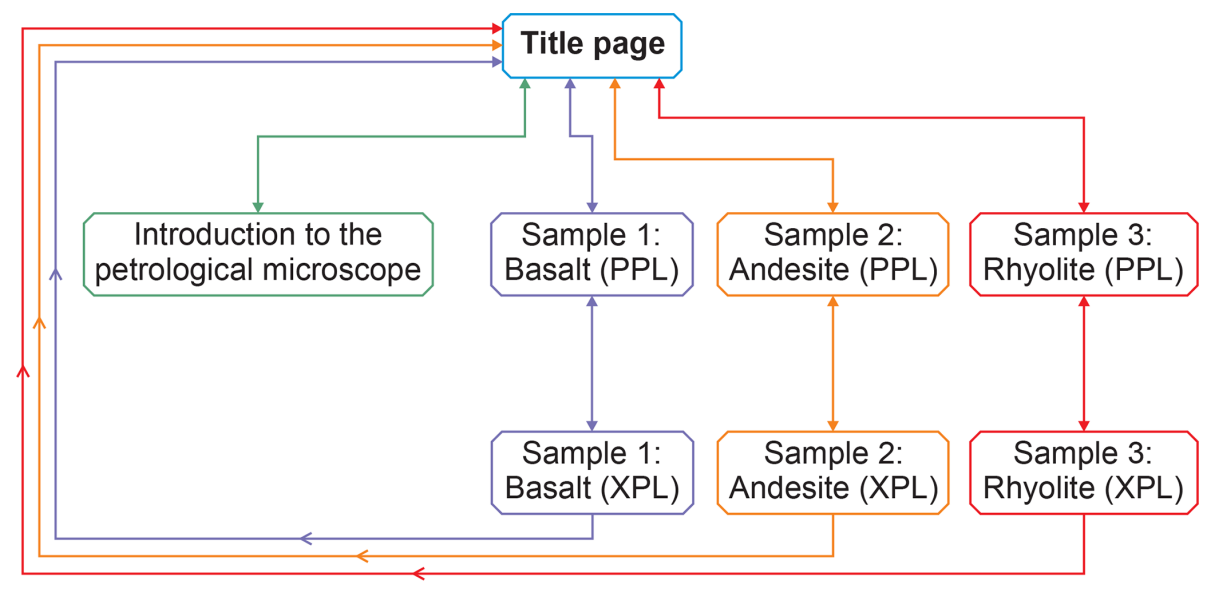

Figure 3. A simplified map highlighting the overall structure of the Thinglink-based learning resource used in this study. Individual interactive images are marked with their titles in a coloured box, and clickable links between images, as well as their direction of travel, are marked with coloured arrows. PPL is the plane-polarized light, and XPL is the cross-polarized light.

\subsection{Theme 2: clarity and quality}

The second theme includes questions 3 and 4 and is focussed on the actual quality of the materials used in the learning resource, including the visual elements (images, videos), the audio elements (voice-overs), and the actual academic quality (scientific content). User responses indicate that the general perception of the resource's clarity was highly positive. One area identified for improvement is the title screen itself, which currently contains no information other than an explanatory voice-over. An easy improvement would be the incorporation of the introductory material as text on the title image. This ties in with the addition of materials aimed at clarifying the scientific terms used in the resource, as well as the standard layout employed for the thin-section images. Another potential challenge regarding clarity is the incorporation of audio narration. This is a powerful tool for inclusivity but was felt to potentially detract from the quality of the resource due to the limitations of using computer-generated speech (e.g. accent, pacing, and pronunciation). Despite this, there exists a motivation for retaining this functionality due to the potential benefits of interaction with a pedagogical agent (e.g. Moreno et al., 2001; VanLehn, 2011), as well as the support it provides for students with additional needs to access the resource. The removal of this functionality on the grounds of moderate inconvenience for able learners is arguably negated by the clear need to support those with additional needs (e.g. visual impairment), and so alternative options such as human speech recordings and a clear means of deactivating the audio may be required. Overall, the feedback indicates that the images and videos used were of sufficient quality for user needs and that the information provided was disseminated clearly.

\subsection{Applicability and pedagogic value}

The third theme comprises questions 5, 7, and 8 and focusses on how applicable the learning resource is in the context of geology and geoscience in higher education (i.e. is the resource applicable to the subject, and does it actually add any real value to the learning experience within the context of experiential and scaffolded learning?). The user responses indicate that there is genuine demand for this style of learning resource, among both learners and teachers. More than $95 \%$ of the combined responses for these questions were positive, and numerous users expressed considerable enthusiasm for the continued development and application of the resource, as well as potential diversification into other areas of geoscience and geography. Student users appear to be particularly interested in an alternative form of learning within the area of petrography, indicating that this style of resource has real value (cf. Choh et al., 2003; Choh and Milliken, 2004; Anand et al., 2010; Lutoshkina et al., 2016). Although classroom-based petrography undoubtedly constitutes experiential learning (Kolb, 2014), the scaffold is arguably far less prominent (Young, 1993), due to the nature of the supplementary materials and educator/learner ratios. The positive responses from the students in this area likely indicate a high demand for alternative learning strategies in this field. The responses for question 7 were particularly positive, indicating that one key issue with this field is the access to a microscope, which limits learning to a classroom environment at specific times. A means of undertaking guided learning for thin-section microscopy could be a powerful pedagogic supplement for existing curricula and could act as a valuable educational component in the context of a blended learning environment. 


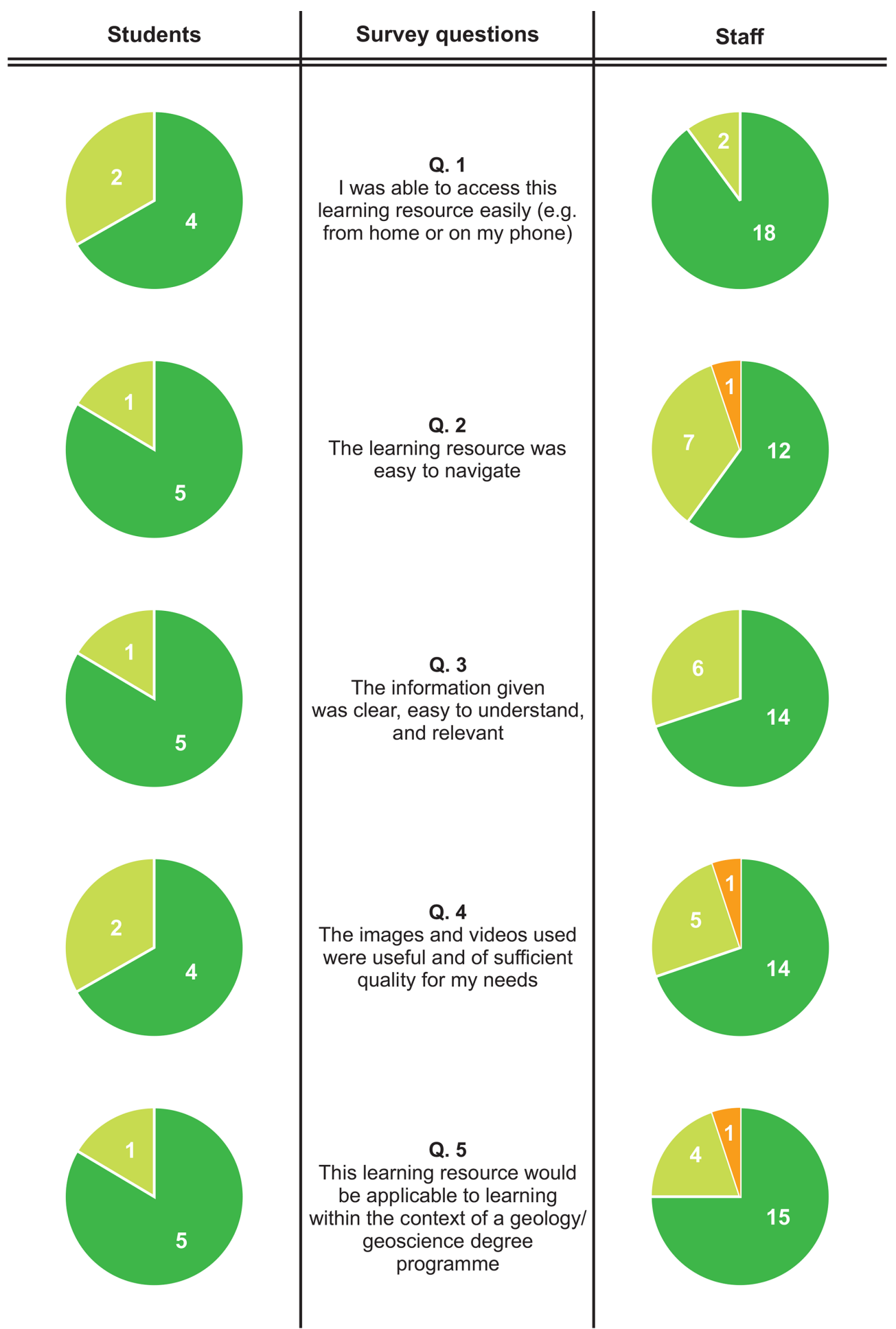

Figure 4. Summarized results of the survey feedback. The number of responses is marked on each section of the charts.

\subsection{Continued resource development}

The fourth and final theme is based around areas of the learning resource which could be improved or expanded and is evaluated via questions 6 and 9. This study indicates that there is a demand amongst students and teachers for an educational resource such as the resource presented here. The majority of users were interested in the inclusion of additional areas of thin-section petrography, such as metamor- 


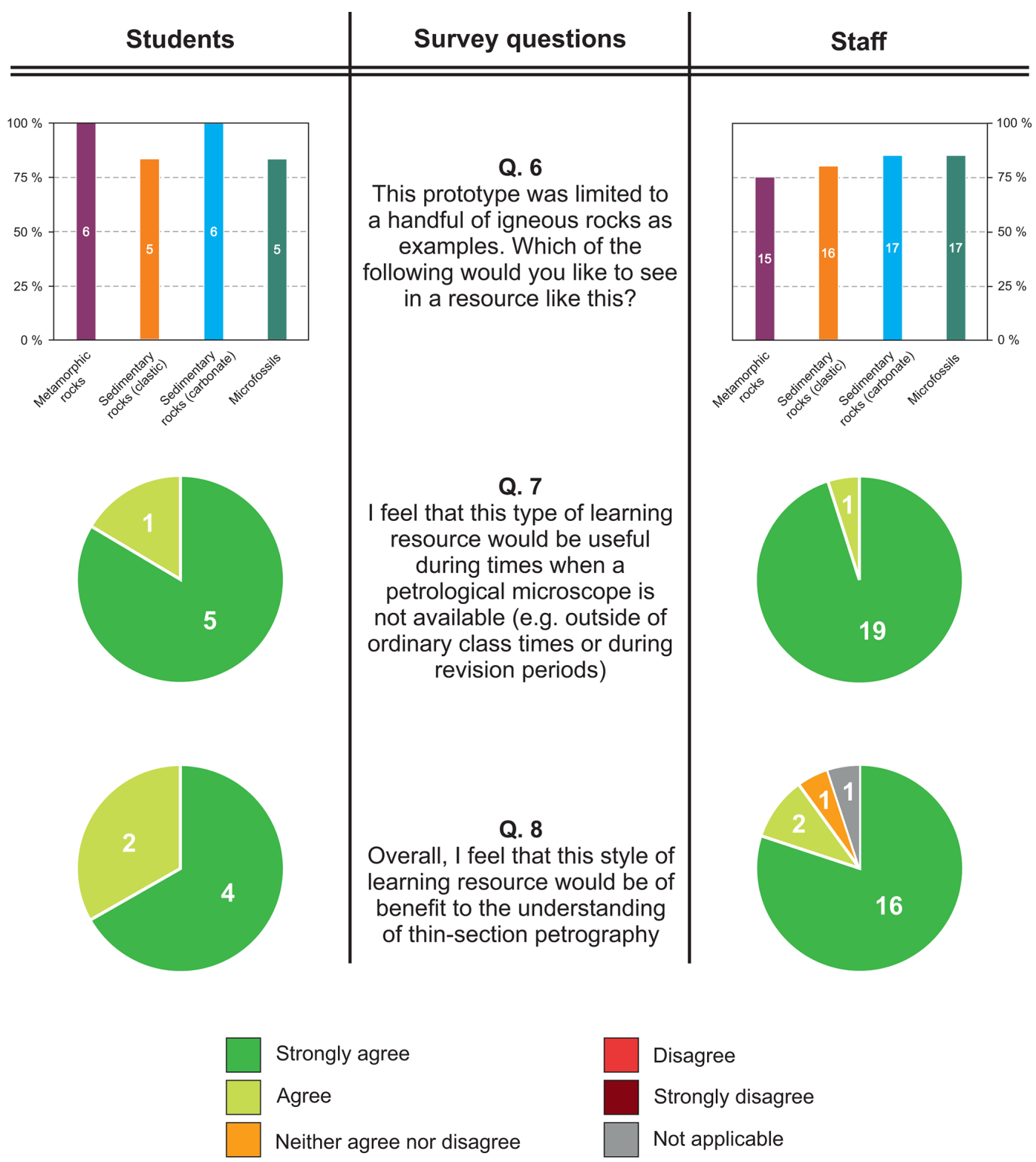

Figure 4. Continued.

phic rocks, highlighting the potential for this resource to be developed and expanded. It is interesting that the student users were arguably more positive about this potential development, suggesting that demand for new supplementary materials in this field may be particularly strong amongst learners. This is consistent with anecdotal evidence experienced by the authors, which implies that students are regularly over-challenged by the field of thin-section petrography and are subsequently deflected into other areas of geoscience that they find more academically accessible. It is very encouraging that so many users would advocate this learning resource's continued development. The feedback provided in this study indicates that the user interface is probably the most significant target for improvement.

\section{Conclusions and moving forward}

The responses from the participants of this study suggest that there is both interest and enthusiasm amongst learners and teachers alike for Thinglink-based interactive online learning resources for thin-section petrography. The resource presented in this study is by no means the first attempt to create a "virtual microscope", but it is innovative in its guided approach to learning, effectively acting as a virtual teacher. It should be noted that the dataset of this study is limited in its size, is not equally distributed between student learners and teaching staff members, and is restricted to a single academic institution. Despite this, users found the platform to be accessible, the images to be of high quality, and the 
Table 1. Additional user comments and suggestions.

\begin{tabular}{lll}
\hline $\begin{array}{l}\text { Response } \\
\text { number }\end{array}$ & Role & Comments and suggestions \\
\hline 1 & Student & $\begin{array}{l}\text { Great idea, very helpful and informative! An interactive exercise where students can identify the rock, min- } \\
\text { erals, and key features would also be helpful. }\end{array}$ \\
\hline 2 & Student & I think it's a really good idea for a resource. \\
\hline 3 & Student & $\begin{array}{l}\text { This would have been really useful during the modules requiring mineral identification in thin sections as } \\
\text { notes can't explain it as well as this visual aid. }\end{array}$
\end{tabular}

4 Student This would have been very useful as an undergraduate as it consolidates information learnt in class, and it allows you to go at your own pace. It has been well put together and presents everything clearly. This resource would be particularly helpful for metamorphic petrology as it can be difficult to understand what you're looking at in the classroom with time restraints/differing samples, etc.

5 Staff Abbreviations (e.g. XPL) used in the introduction should be expanded in the introduction to make sure all users know what is available. Could this also be put next to the button that polarizes the light? I love the home page (LOVE IT!) - replicates what your workstation might look like in real life (ish), but one thing to note is that the text on the slide might be difficult to see for some users or if you are using a phone. Can you have something where a larger text box pops up when you put the mouse over the coloured button? It might also be helpful for the rock type name to be on the screen when you go to the slide itself. I know it's up on the "i" button but that might not be clear straight away. Also, on my MacBook (maybe it's different on a PC?), the "i" button is lying really closely behind the "+" button. This might be an issue for some users if they keep accidentally clicking on polarize rather than the info button. Also it's kind of hidden, so might be overlooked. Could the "i" button be moved over to the middle? Or maybe the polarizing button into the middle so that you keep the symmetry of the yellow buttons on each side. I think this would be a fantastic resource! It would be great to see this used for microfossil analyses and also to teach about tephra (microtephra slides).

6 Staff The introductory sound track should have a text description/closed captioning for those without sound/hearing impaired. Having it auto-run returning from viewing a thin section would get annoying with a lot of specimens. There are a few UI/UX issues I think - what is the significance of the magnifying glass vs. question mark symbol - would a numbered sequence work better? (I would click on a "1" but don't know where to start or what I'm supposed to be doing at present). Images should be clearly labelled plane-polarized light (PPL) and cross-polarized light (XPL) and have the +/- icon clearly labelled as a PPL/XPL switch. As well as explaining what PPL/XPL are, maybe "technical" terms like relief and interference should be clarified to help the student to know what to look for (e.g. the bright reds and blues of second-order interference colours). Does Petra's voice actually add anything? It might for visually impaired students, but they won't be able to see the thin-section photos or know where to click on them. Don't get me wrong - I think this will turn out to be a very good resource, but I think the UI need some tweaking.

$7 \quad$ Staff Viewing the thin-section slides under the microscope reveals some icons that identify and explain features when clicked on. Why are there two different icons (question mark vs. magnifying glass)? There appears to be no functional difference. For the question mark icons I was thinking there would be a question explained or a question posed to the viewer at the end of the explanation (i.e. the ? indicates there is a question). But the question mark vs. magnifying glass icons seem to be used interchangeably, whether or not a question is involved. When viewing a slide, it would be good to know what pressing the "+" button does. I can see it changes something, but exactly what I am not sure (light source?). The microscope image with markers that identify key features is very good. Can Petra be given a British accent? Or maybe French ...

8 Staff This is fantastic! This will be a great resource to help students when working remotely or for revision purposes. Some minor points/suggestions would be to have a bit more text on the main screen as it took me a while to find the microscope part, which is really useful to know the difference between XPL and PPL. For each thin section it would also be useful to have some blurb about each rock time from which the thin section originated, i.e. photo of the rock and where it was taken from. This might help students to put it into context? I really liked the descriptions provided, clear and just enough text too. This has endless potential to be rolled out to other disciplines and equipment too, great work on a valuable and usable resource.

9 Staff Great stuff. Well done! Just some observations... when opening the first thin section, a "+" symbol appears in the upper right corner. I first thought this is to change the zoom but realized it is for switching to crossed nicols. On the slides where there are some questions and some magnifying glass symbols. When clicking on a magnifying glass symbol a mineral or other phase is explained in detail. I even learned something about pyroxene which I had forgotten. Thank you, Adam, for putting this together. When clicking on a question mark symbol, also some information appears. Is there any difference between the question mark and magnifying glass symbols in regard to what content they show? 
Table 1. Continued.

\begin{tabular}{|c|c|c|}
\hline $\begin{array}{l}\text { Response } \\
\text { number }\end{array}$ & Role & Comments and suggestions \\
\hline 10 & Staff & $\begin{array}{l}\text { The }+/- \text { to switch between PPL and XPL wasn't obvious as a feature when first entered (thought it was } \\
\text { magnification). Perhaps some intro guide or pop up on how to navigate/use features? Would be useful to have } \\
\text { an arrow on the pop up images for the microscope slides to show exactly what crystal/point is being referred } \\
\text { to, e.g. "olivine" pop-up on the basalt slide - highlight which is the olivine and which is the feldspar as talk } \\
\text { about both being clear. Maybe too have yourself narrating the text rather than immersive reader? Appreciate } \\
\text { it might be an unreasonable amount of work though - and unwieldy as you'd need to record if you edited any } \\
\text { text. Great stuff, enjoyed it. Thanks. }\end{array}$ \\
\hline 11 & Staff & $\begin{array}{l}\text { Some other feedback: (1) the start isn't clear, maybe some introductory text or a header? (2) The voice is } \\
\text { a little grating! (3) Some phrases probably need explaining to be useful for the very basics, i.e. XPL and } \\
\text { PPL, and some links for key terms would be useful. (4) It is not clear what the difference is between the } \\
\text { search icon and the question mark icon on the slides. (5) The XPl and PPL symbols are not clear as to how } \\
\text { to change between and it is positioned on the info button - I wouldn't normally click on an info button, but } \\
\text { this was important intro material - make clearer as a first point of access? (6) Love the rotation under XPL - } \\
\text { plagioclase discusses rotation but doesn't do it. }\end{array}$ \\
\hline 12 & Staff & $\begin{array}{l}\text { I really struggled with thin-section work during my degree. The main problem was that everyone was look- } \\
\text { ing at different things. This learning resource overcomes that problem and would be great for introductory } \\
\text { microscope work. It could be used as part of a flipped learning approach, allowing students to come to a } \\
\text { practical more prepared, and would help relieve anxiety for those who struggle with the topic. It would also } \\
\text { be really useful for revision and recap and would fit in nicely with anyone's schedule (as it doesn't require } \\
\text { any equipment or access to physical thin sections). Really impressive, good work. }\end{array}$ \\
\hline 13 & Staff & $\begin{array}{l}\text { This resource was not only informative; the format was really clear and engaging. It would be great to use } \\
\text { it to present how samples are presented and what the same minerals look like in the bulk form. I am not } \\
\text { a geologist, but I found the material interesting. As a non-specialist I would need to look up some of the } \\
\text { technical terms - but I guess if this was aimed at me, the terms could be described in more detail in the } \\
\text { descriptions with a "more information" option somewhere. }\end{array}$ \\
\hline 14 & Staff & $\begin{array}{l}\text { It's not clear what the difference between the question mark and the hand lens is - both symbols lead to } \\
\text { additional information in a similar format. On my computer, the "i" symbol with information about the rock } \\
\text { type was somewhat hidden underneath the + and - symbols; information about the rock type could perhaps } \\
\text { be placed in a more accessible position? }\end{array}$ \\
\hline 15 & Staff & $\begin{array}{l}\text { Definitely useful for both UG/MSc teaching, revision, and even transitioning from FE to HE. Audio also helps } \\
\text { it make more understandable and reinforces learning. I would recommend changing accents; Irish accents are } \\
\text { positively received from GPS navigation in cars apparently. }\end{array}$ \\
\hline 16 & Staff & $\begin{array}{l}\text { Not keen on Petra, should replace with Adam instead! Consider making the voice-over optional as most } \\
\text { individuals can read faster listening to a narrative. Has the potential to make an excellent resource for online } \\
\text { geology teaching - well done! }\end{array}$ \\
\hline 17 & Staff & $\begin{array}{l}\text { Not sure if it is possible, but it would be useful that the bits that have been already seen change colour or } \\
\text { shape, so students know what they have already seen. Also, what is the difference between the magnifying } \\
\text { glass and the question mark? }\end{array}$ \\
\hline 18 & Staff & $\begin{array}{l}\text { Fascinating introduction to microscopy! Engaging and easy to navigate. This is an excellent online resource } \\
\text { - wider use on the geography programmes would be most welcome. }\end{array}$ \\
\hline 19 & Staff & Fantastic resource which has huge applications across geoscience and geography programmes. \\
\hline 20 & Staff & Amazing resource, really well thought through, with excellent interactive elements. \\
\hline 21 & Staff & The inclusion of audio in addition to text is really good, inclusive practice. \\
\hline 22 & Staff & A most attractive resource, easy to use, and well presented. \\
\hline
\end{tabular}



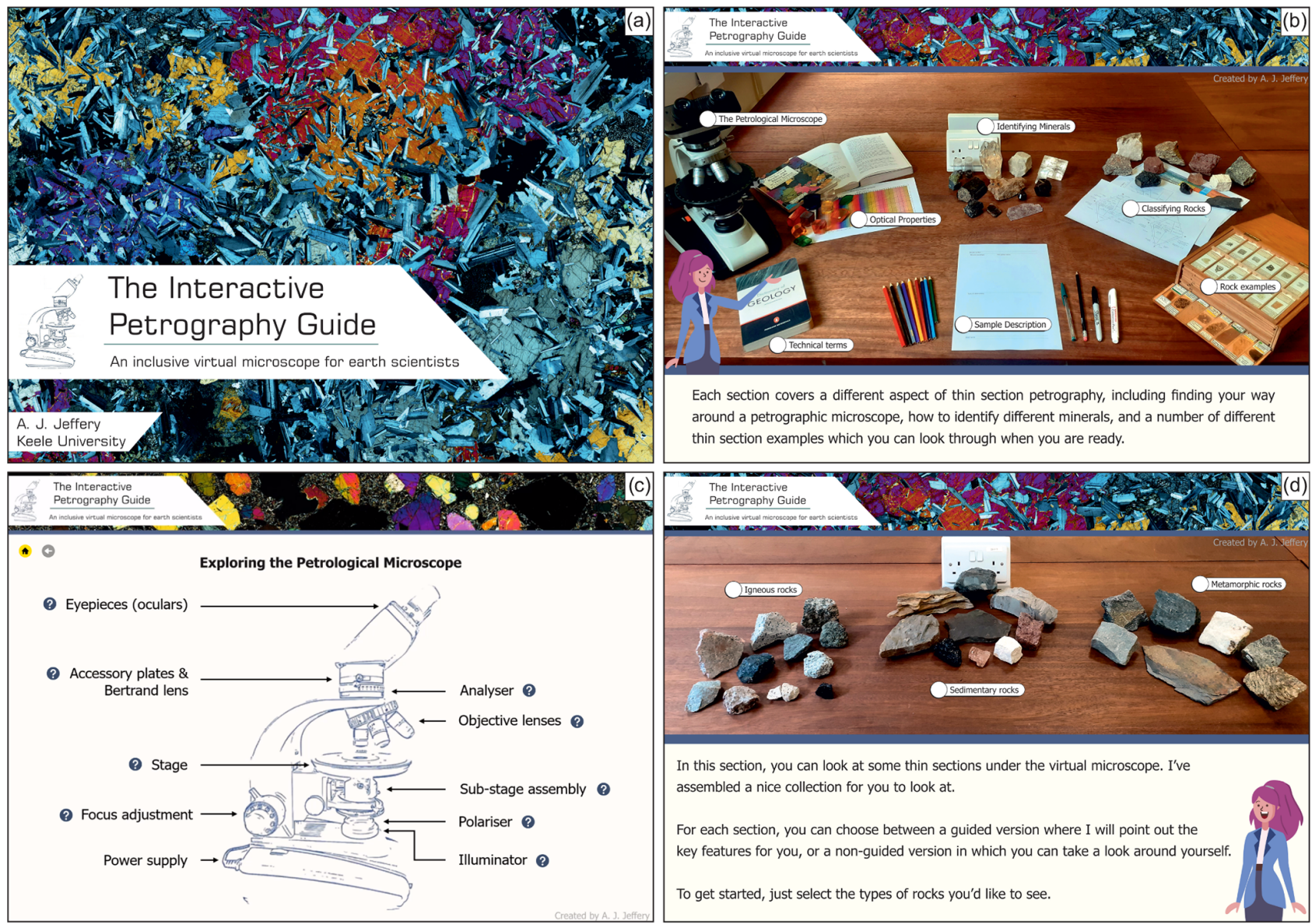

Each section covers a different aspect of thin section petrography, including finding your way around a petrographic microscope, how to identify different minerals, and a number of different thin section examples which you can look through when you are ready.

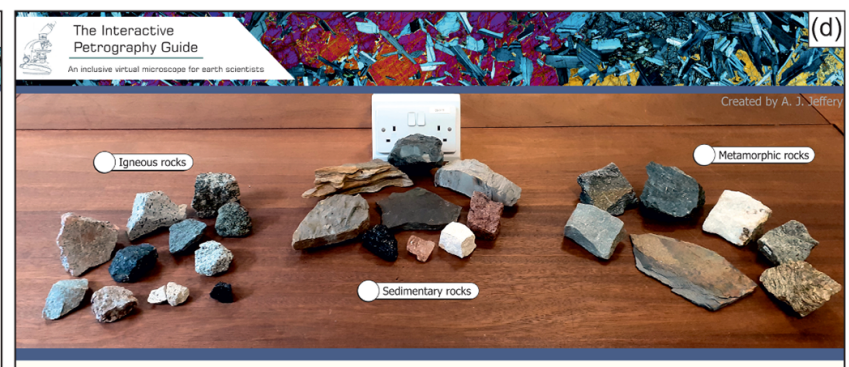

In this section, you can look at some thin sections under the virtual microscope. I've assembled a nice collection for you to look at.

For each section, you can choose between a guided version where I will point out the key features for you, or a non-guided version in which you can take a look around yourself. To get started, just select the types of rocks you'd like to see.
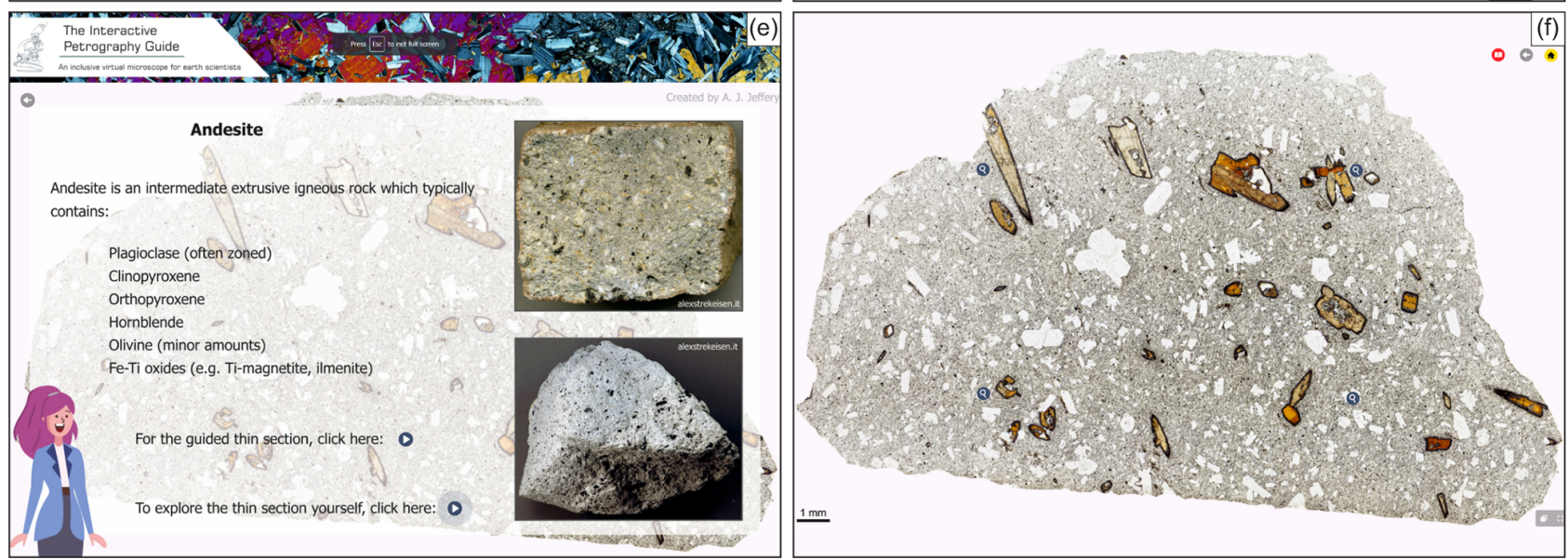

Figure 5. Representative screenshots of a new microscopy resource currently being constructed based on the feedback of this study. Cartoon avatar designed by pikisuperstar/Freepik. (a) Main title screen. (b) Home page with various clickable icons leading to learning materials. (c) Example learning material with various interactive elements. (d) Example submenu in which users can select the type of rock samples to view under the microscope. (e) Example information screen prior to viewing sample under microscope. (f) Example thin-section image with interactive elements.

information clearly disseminated and relevant. Many of the staff users expressed interest in applying Thinglink to their own teaching materials, whereas student users were particularly interested in the visual and hands-on style (compared with written notes) and the potential to complete thin-section study at their own pace. Some staff even referred to their own undergraduate degree and how useful this form of resource would have been. This level of positivity likely reflects a gen- 
uine desire amongst both learners and educators for diversification in this area of education, moving away from traditional approaches and incorporating more flexible, blended approaches. Key criticisms revealed in the dataset relate primarily to the user interface, which many found to be slightly confusing as it was not made sufficiently clear what the various interactive icons would do. For some users, the automated narration (termed Petra) was a major negative point, although others felt it was fundamental for increasing inclusivity and accessibility. The majority of the responses indicate that a resource of this type would be beneficial to learning and that there is both scope and demand for expansion of the project.

This study offers some preliminary insight into the needs of students engaged with thin-section petrography and acts as a foundation to potential larger studies on the use of imagebased guided virtual petrography. Based upon the results of this study, the interactive petrography resource presented here will be developed further, taking into consideration the feedback provided. As such, the key areas for further improvement are as follows:

- provision of a tutorial page which explains the various icons that are used throughout;

- repositioning of the icons to minimize interface difficulties such as overlapping hotspots;

- review of audio narration and potential recording of an alternative "human" or "authentic" voice;

- detailed review of accessibility relating to specific learning requirements aiming to maximize inclusivity;

- addition of new material to expand existing thin-section images.

- potential inclusion of $360^{\circ}$ imagery to create a virtual classroom/laboratory;

- expansion of academic material into additional areas, including other rock types, and the addition of theoretical course materials (e.g. explanation of polarizing light microscope or definitions of scientific terms used throughout).

Similarly, and in order to address the limitation of this preliminary study, the continuing development of this project will involve the collection of a larger and more diverse dataset, including different institutions and academic levels (e.g. further education vs. higher education).

Overall, this study highlights an exciting opportunity to provide an innovative learning resource which complements existing resources and fills an academic niche. The platform facilitates free, highly adaptive, inclusive, and distance learning, mitigates many of the pedagogical challenges that exist within an academic area which is dependent upon access to microscopes, and hopefully goes some way towards bridging the gap between the classical scientific field of petrography and the modern learner. Although considerable focus in recent years has been given to the potential use of Thinglink for virtual fieldwork, incorporating $360^{\circ}$ imagery, we feel that augmented two-dimensional imagery has just as much potential for laboratory-based virtual learning. Resources such as the one presented here have potential for use as stand-alone resources or as supplements to other virtual learning experiences, such as virtual fieldwork, allowing learners to gain virtual access not only to the field, but also the laboratory (e.g. being able to investigate rocks in the field and then in the virtual lab, under a virtual microscope). Based upon the study presented here, a new resource is currently being developed, taking into account the feedback provided, as well as adding new functionality (Fig. 5). This resource includes enhanced images and a distinct home page from which a variety of modules can be reached. For example, a number of additional sections have been added providing guidance on topics such as mineral identification and optical properties, a glossary of terms, and guidance on sample description. Furthermore, the resource includes a considerable range of rock types, aiming to cover the key lithologies and textures that might be required for a PMG-based course in higher or further education.

Data availability. The anonymized data used for this study are stored securely at Keele University.

Author contributions. The project was conceived, designed, and implemented by AJJ, SLR, and KLAJ. The learning resource was created by AJJ, with assistance from LH. The manuscript was prepared by AJJ, with contributions from all co-authors.

Competing interests. The authors declare that author Steven L. Rogers is a member of the editorial board of the journal. The remaining authors declare no conflict of interest.

Acknowledgements. This paper was greatly improved by the constructive reviews of Jamie Pringle and Edward McGowan. We are grateful to Mirjam Sophia Glessmer for editorial handling. The authors are extremely grateful to those who participated in the project and provided feedback on the presented learning resource. Facilities required for this project were provided by the School of Geography, Geology, and the Environment, Keele University. This study was undertaken for module EDU-40092 as part of the lead author's MA in Teaching and Learning in Higher Education.

Review statement. This paper was edited by Mirjam Sophia Glessmer and reviewed by Jamie Pringle and Edward McGowan. 


\section{References}

Anand, M., Pearson, V., Kelley, S., Tindle, A., Whalley, P., and Koeberl, K.: Virtual microscope for extra-terrestrial samples, 43rd Lunar and Planetary Science Conference, European Planetary Science Congress, 2012, The Woodlands, Texas, USA, 10, 2012.

Anderson, L. W., Krathwohl, D. R., Airasian, P. W., Cruikshank, K. A., Mayer, R. E., Pintrich, P. R., Raths, J., and Wittrock, M. C.: A Taxonomy for Learning, Teaching, and Assessing: A revision of Bloom's Taxonomy of Educational Objectives, Pearson, Allyn and Bacon, New York, 2001.

Appasamy, P.: Fostering student engagement with digital microscopic images using Thinglink, an image annotation program, Journal of College Science Teaching, 47, 16-21, https://doi.org/10.2505/4/jcst18_047_05_16, 2018.

Argles, T., Minocha, S., and Burden, D.: Virtual field teaching has evolved: benefits of a 3D gaming environment, GeologyToday, 31, 222-226, https://doi.org/10.1111/gto.12116, 2015.

Ariskin, A. A. and Nielsen, R. L.: Application of computer simulation of magmatic processes to the teaching of petrology, J. Geol. Educ., 41, 438-441, https://doi.org/10.5408/0022-136841.5.438, 1993.

Barker, A. J.: A key for identification of rock-forming minerals in thin section, CRC Press, Boca Raton, https://doi.org/10.1201/b17437, 2014.

Bonk, C. J. and Graham, C. R.: The handbook of blended learning: Global perspectives, local designs, John Wiley and Sons, San Francisco, USA, 2012.

Brady, J. B.: Magma in a beaker: Analog experiments with water and various salts or sugar for teaching igneous petrology, Canadian Mineral., 47, 457-471, https://doi.org/10.3749/canmin.47.2.457, 2009.

Childers, G., and Jones, M. G.: Students as Virtual Scientists: An exploration of students' and teachers' perceived realness of a remote electron microscopy investigation, Int. J. Sci. Educ., 37, 15, 2433-2452, https://doi.org/10.1080/09500693.2015.1082043, 2015.

Choh, S.-J. and Milliken, K. L.: Virtual carbonate thin section using PDF: new method for interactive visualization and archiving, Carbonate. Evaporite., 19, 87-92, https://doi.org/10.1007/bf03178472, 2004.

Choh, S.-J., Milliken, K. L., and McBride, E. F.: A tutorial for sandstone petrology: architecture and development of an interactive program for teaching highly visual material, Comput. Geosci., 29, 1127-1135, 2003.

Cliffe, A. D.: A review of the benefits and drawbacks to virtual field guides in today's Geoscience higher education environment, International Journal of Educational Technology in Higher Education, 14, 28, https://doi.org/10.1186/s41239-017-0066-x, 2017.

Deer, W. A., Howie, R. A., and Zussman, J.: An introduction to the rock-forming minerals, Longman Group Limited, London, https://doi.org/10.1180/DHZ, 1966.

Domagk, S., Schwartz, R. N., and Plass, J. L.: Interactivity in multimedia learning: An integrated model, Comput. Hum. Behav., 26, 1024-1033, https://doi.org/10.1016/j.chb.2010.03.003, 2010.

Domingo, J. R. and Bradley, E. G.: Education student perceptions of virtual reality as a learning tool, J. Educ. Tech. Syst., 46, 329342, https://doi.org/10.1177/0047239517736873, 2018.
Dutrow, B. L.: Visual communication: Do you see what I see?, Elements, 3, 119-126, https://doi.org/10.2113/gselements.3.2.119, 2007.

Emley, D. W., Rowbotham, G., and Lees, G. J.: Optical Mineralogy (Version 2), UK Earth Science Courseware Consortium, University of Manchester, Manchester, UK, 1998.

Evans, C. and Gibbons, N. J.: The interactivity effect in multimedia learning, Comput. Educ., 49, 1147-1160, https://doi.org/10.1016/j.compedu.2006.01.008, 2007.

Folk, R. L.: Henry Clifton Sorby (1826-1908), the founder of petrography, J. Geol. Educ., 13, 43-47, https://doi.org/10.5408/0022-1368-xiii.2.43, 1965.

Frost, M. J.: Two computer programs for teaching igneous petrology, J. Geol. Educ., 25, 148-149, https://doi.org/10.5408/00221368-25.5.148, 1977.

Graham, C. R.: Blended learning systems, Definition, Current Trends, and Future Directions, in: The handbook of blended learning: Global perspectives, local designs, edited by: Bonk, C. J. and Graham, C. R., 3-21, 2006.

Granshaw, F. D. and Duggan-Haas, D.: Virtual fieldwork in geoscience teacher education: Issues, techniques, and models, Geol. S. Am. S., 492, 285-303, https://doi.org/10.1130/2012.2492(20), 2012.

Gribble, C. D. and Hall, A. J.: Optical mineralogy: Principles \& practice, UCL Press, London, UK, https://doi.org/10.1007/9781-4615-9692-9, 1992.

Gunter, M. E.: The polarized light microscope: Should we teach the use of a 19th century instrument in the 21st century?, J. Geol. Educ., 52, 34-44, https://doi.org/10.5408/1089-999552.1.34, 2004

Hannafin, M. J. and Peck, K. L.: The design, development, and evaluation of instructional software, MacMillan, New York, 1988.

Houghton, J. J., Lloyd, G. E., Robinson, A., Gordon, C. E., and Morgan, D. J.: The Virtual Worlds Project: geological mapping and field skills, GeologyToday, 31, 227-231, https://doi.org/10.1111/gto.12117, 2015.

Kolb, A. Y. and Kolb, D. A.: Learning styles and learning spaces: Enhancing experiential learning in higher education, Acad. Manag. Learn. Edu., 4, 193-212, https://doi.org/10.5465/amle.2005.17268566, 2005.

Kolb, D. A.: Experiential learning: Experience as the source of learning and development, FT press, Barcelona, Spain, 2014

Kolb, D. A., Boyatzis, R. E., and Mainemelis, C.: Experiential learning theory: Previous research and new directions, Perspectives on Thinking, Learning, and Cognitive Styles, 1, 227-247, https://doi.org/10.4324/9781410605986-9, 2001.

Krathwohl, D. R.: A Revision of Bloom's Taxonomy: An Overview, Theor. Pract., 41, 212-218, https://doi.org/10.1207/s15430421tip4104_2, 2002.

Legislation.gov.uk: Equality Act 2010, available at: http://www. legislation.gov.uk/ukpga/2010/15/contents (last access: $27 \mathrm{Au}-$ gust 2020), 2010.

Lutoshkina, O., Zabrodina, I., Yakich, T., and Slesarenko, I.: Using electronic resources when delivering the module of mineralogy and petrography in english as a way to motivate students (as illustrated by blogging), Proceedings of Edulearn 16 Conference, Barcelona, Spain, 6002-6008, 2016. 
Mackenzie, W. and Adams, A.: Rocks and minerals in thin section, Manson Publishing, London, https://doi.org/10.1201/9781315116365, 1994.

Mackenzie, W. and Guildford, C.: Atlas of rock forming minerals in thin section, Long Man, London, https://doi.org/10.4324/9781315837413, 1980.

Manduca, C. A.: Improving instruction in mineralogy, Petrology, and Geochemistry - lessons from research on learning, Elements, 3, 95-100, https://doi.org/10.2113/gselements.3.2.95, 2007.

Mayer, R. E., Dow, G. T., and Mayer, S.: Multimedia Learning in an Interactive Self-Explaining Environment: What Works in the Design of Agent-Based Microworlds?, J. Educ. Psychol., 95, 806812, https://doi.org/10.1037/0022-0663.95.4.806, 2003.

Milliken, K. L., Barufaldi, J. P., McBride, E. F., and Choh, S. J.: Design and assessment of an interactive digital tutorial for undergraduate-level sandstone petrology, J. Geosci. Educ., 51, 381-386, https://doi.org/10.5408/1089-9995-51.4.381, 2003.

Mogk, D. W.: Teaching mineralogy, petrology, and geochemistry, New directions at the intersection of research about Earth and research on learning, Elements, 3, 93-94, https://doi.org/10.2113/gselements.3.2.93, 2007.

Moreno, R., Mayer, R. E., Spires, H. A., and Lester, J. C.: The case for social agency in computer-based teaching: do students learn more deeply when they interact with animated pedagogical agents?, Cognition Instruct., 19, 177-213, https://doi.org/10.1207/S1532690XCI1902_02, 2001.

Nakatsuka, K.: Making History Come to Life: ThingLink Virtual Museums, Social Studies Review, 57, 47-52, available at: https://search.proquest.com/scholarly-journals/ making-history-come-life-thinglink-virtual/docview/

2344260092/se-2?accountid=11814 (last access: 8 March 2021), 2018/19.

Palmer, D. C., Tindle, A. G., and Crompton, S.: Digital Microscope, CD S260 Geology Block 2, The Open University, Milton Keynes, 1999.

Peck, W. H.: Teaching metastability in petrology using a guided reading from the primary literature, J. Geosci. Educ., 52, 284288, https://doi.org/10.5408/1089-9995-52.3.284, 2004.

Penn, R. L., Flynn, L., and Johnson, P.: Building a successful middle school outreach effort: Microscopy camp, J. Chem. Educ., 84, 955-960, https://doi.org/10.1021/ed084p955, 2007.

Perkins, D.: The case for a cooperative studio classroom: teaching petrology in a different way, J. Geosci. Educ., 53, 101-109, https://doi.org/10.5408/1089-9995-53.1.101, 2005.

Pringle, J. K.: Educational environmental geoscience e-gaming to provide stimulating and effective learning, Higher Education Planet, 27, 21-28, https://doi.org/10.11120/plan.2013.27010021, 2013.
Pringle, J. K.: Educational egaming: the future for geoscience virtual learners?, GeologyToday, 30, 145-148, https://doi.org/10.1111/gto.12058, 2014.

Pringle, J. K.: Virtual geology special issue: developing training, teaching and research skillsets for geoscientists, GeologyToday, 31, 213-215, https://doi.org/10.1111/gto.12118, 2015.

Reinhardt, J.: Optical mineralogy in a modern earth sciences curriculum, J. Geosci. Educ., 52, 60-67, https://doi.org/10.5408/1089-9995-52.1.60, 2004.

Riley Brice, W. and Hawkins Lint, B.: A manual of photographs as a teaching tool in petrography, J. Geol. Educ., 35, 206-207, https://doi.org/10.5408/0022-1368-35.4.206, 1987.

Rogers, S. L.: Cheap, accessible, and virtual experiences as tools for immersive study: a proof of concept study, Research in Learning Technology, 28, 1-15, https://doi.org/10.25304/rlt.v28.2416, 2020.

Selwyn, N.: The use of computer technology in university teaching and learning: a critical perspective, J. Comput. Assist. Learn., 23, 83-94, https://doi.org/10.1111/j.1365-2729.2006.00204.x, 2007.

Shin, Y. S.: Virtual experiment Environment's design for science education, International Journal of Distance Education Technologies, 2, 62-76, https://doi.org/10.4018/jdet.2004100104, 2004.

Squire, K. D.: Video game-based learning: an emerging paradigm for instruction, Performance Improvement Quarterly, 21, 7-36, https://doi.org/10.1002/piq.21139, 2008.

Stokes, A., Feig, A. D., Atchison, C. L., and Gilley, B.: Making geoscience fieldwork inclusive and accessible for students with disabilities, Geosphere, 15, 1809-1825, https://doi.org/10.1130/ges02006.1, 2019.

Thinglink.com: Annotate images and videos - ThingLink, available at: http://www.thinglink.com (last access: 3 March 2021), 2018.

VanLehn, K.: The relative effectiveness of human tutoring, intelligent tutoring systems, and other tutoring systems, Educ. Psychol., 46, 197-221, https://doi.org/10.1080/00461520.2011.611369, 2011.

Waddoups, G. L. and Howell, S. L.: Bringing online learning to campus: The hybridization of teaching and learning at Brigham Young University, The Int. Rev. Res. Open Dis., 2, 1-21, https://doi.org/10.19173/irrodl.v2i2.52, 2002.

Writh, K. R.: Teaching for deeper understanding and lifelong learning, Elements, 3, 107-111, https://doi.org/10.2113/gselements.3.2.107, 2007.

Young, M. F.: Instructional design for situated learning, ETR\&D-Educ. Tech. Res., 41, 43-58, https://doi.org/10.1007/BF02297091, 1993. 